\title{
A theory-based evaluation of a community-based funding scheme in a disadvantaged suburban city area
}

\author{
Gráinne Hickey $^{\mathrm{a}, *}$, Sinead McGilloway ${ }^{\mathrm{a}}$, Morgan O’Brien ${ }^{\mathrm{a}, 1}$, Yvonne Leckey ${ }^{\mathrm{a}}$, \\ Maurice Devlin ${ }^{\mathrm{b}}$ Work carried out in Maynooth University Department of Psychology, \\ Maynooth University
}

\footnotetext{
a Maynooth University Department of Psychology, National University of Ireland Maynooth, Co., John Hume Building, North Campus, Kildare, Ireland

${ }^{\mathrm{b}}$ Maynooth University Department of Applied Social Studies, National University of Ireland Maynooth, Co., Laraghbryan House, North Campus, Kildare, Ireland
}

\section{A R T I C L E I N F O}

\section{Article history:}

Received 9 September 2014

Received in revised form 6 March 2015

Accepted 12 March 2015

Available online 8 April 2015

\section{Keywords:}

Community development funds

Program development

Program theory

Theory-based evaluation

Community-driven development

\begin{abstract}
A B S T R A C T
Community-driven development (CDD) initiatives frequently involve funding schemes which are aimed at channelling financial investment into local need and fostering community participation and engagement. This exploratory study examined, through a program theory approach, the design and implementation of a small-scale, community-based fund in Ireland. Observations, documentary analysis, interviews and group discussions with 19 participants were utilized to develop a detailed understanding of the program mechanisms, activities and processes, as well as the experiences of key stakeholders engaged with the funding scheme and its implementation. The findings showed that there were positive perceptions of the scheme and its function within the community. Overall, the availability of funding was perceived by key stakeholders as being beneficial. However, there were concerns over the accessibility of the scheme for more marginalized members of the community, as well as dissatisfaction with the openness and transparency surrounding funding eligibility. Lessons for the implementation of small-scale CDD funds are elaborated and the utility of program theory approaches for evaluators and planners working with programs that fund community-based initiatives is outlined.
\end{abstract}

(C) 2015 Elsevier Ltd. All rights reserved.

\section{Introduction}

Development programs and policy initiatives are increasingly identifying communities as agents of change (Labonne \& Chase, 2011). Although bottom-up development has long been in the lexicon of community-development practitioners, communitydriven development (CDD) has gradually gained popularity at a policy level (Eversole, 2010; Tandon, 2008). Arguably, CDD has many benefits including facilitating participation, redressing power imbalances and helping to create agency and empowerment within the community (Mansuri \& Roa, 2003).

CDD encompasses poverty reduction strategies which support the participation of community members in key development decisions and often involves the empowerment of communities by

\footnotetext{
* Corresponding author. Tel.: +3531 108 6658; fax: +3531 1084767 .

E-mail addresses: grainne.hickey@nuim.ie (G. Hickey), sinead.mcgilloway@nuim.ie(S. McGilloway),morgan.obrien@itcarlow.ie(M. O’Brien) yvonne.leckey@nuim.ie (Y. Leckey), maurice.devlin@nuim.ie (M. Devlin).

1 Current address: Department of Humanities, Institute of Technology Carlow, Kilkenny Rd., Carlow, Ireland.
}

means of financial or monetary support (Nuttavuthisit, Jindahra, \& Prasarnphanich, 2014). For example, social funds form a CDD strategy (Caravalho \& White, 2004) and are aimed at channelling financial investments into meeting local needs. These kinds of funding schemes differ from traditional anti-poverty strategies in that they fund locally-initiated proposals, rather than involving previously identified development programs (Rawlings, Sherburne-Benz, \& Van Domelen, 2003). Social funds provide communities with opportunities to prepare subproject proposals, compete for grants and hold responsibility for the implementation and maintenance of the financial investment. A key objective of such CDD funds is the assimilation of community assets and resources into development processes. Thus, community members are actively involved in the development process, rather than being the targets of poverty reduction strategies (Narayan \& Ebbe, 1997). Social funds are thought to have many advantages including better responsiveness to community needs, an augmented awareness of - and access to information, greater efficiency and efficacy of service delivery and enhanced sustainability (Mansuri \& Roa, 2003). It has also been argued that social funds enhance community participation by investing control over decisions to marginalized persons and by 
facilitating participatory experiences which, in turn, result in the enhancement of social networks within and across the community. In this way, funding is thought to empower and enable communities to better implement and sustain future developmental processes (Labonne \& Chase, 2011).

A general assumption inherent in CDD funding schemes is that given facilitated opportunities, community members will be willing to participate in community development processes. However, there are barriers which may undermine such engagement (Nuttavuthisit et al., 2014), such as cultural values and norms, constraints around roles, responsibilities and capabilities, as well as lack of experience (Cornwall, 2003, 2008). Thus, participation, in spite of the availability of platforms, can be very difficult to achieve. Moreover, non-participation may not necessarily mean that those individuals or groups are socially excluded; rather, non-participation may be a preferential situation, adopted from a position of power (Shortall, 2008). Debate has further arisen over whether social funds, and - more generally - participative approaches, are truly participatory (Arcand \& Bassol, 2006). Eversole (2010) argues that participatory initiatives tend to situate participation within community-based programs and therefore, sustain, rather than reverse, extant power structures. Social funds have been further criticized for being open to 'elite capture' whereby community members and/or groups with pre-existing high levels of resources are more likely to be successful in obtaining and managing social funds. 'Participatory' projects, therefore, can be appropriated by local elites-politically, socioeconomically or culturally elite members of the community (Caravalho \& White, 2004; Fritzen, 2007).

CDD funds are growing in popularity (Van Domelen, 2006) and increasingly, funding schemes are being used by NGOs, philanthropic organizations, governmental bodies and other organizations to support bottom-up community development (Perrett, 2004). However, funding schemes may not be an optimal mechanism for promoting community participation in all circumstances. For example, as outlined above, there may be many barriers to engagement or funding mechanisms may be insufficient to encourage participation. Thus, more research is needed to explore and examine the mechanisms and assumptions underlying the operation of these kinds of CDD funds. It is also pertinent to explore how community members perceive these schemes and their attendant benefits or drawbacks. For example, when and how community members are prompted and/or enabled to engage with funding initiatives is important to explore. Understanding stakeholders' perspectives of funding schemes can also help in highlighting some of the conditions under which CDD funding initiatives may be most acceptable to local communities and for whom are they most beneficial.

In this study the functioning of a community-based funding scheme and its implementation within a disadvantaged suburban community in the Republic of Ireland was explored. The funding scheme, named Literacivic, was established as part of a large-scale community change initiative (CCI) called Youngballymun, and provided financial support for CDD initiatives. Specifically, the aim of the Literacivic scheme was to encourage and support bottom-up community development processes through the financial incentivization of locally-developed subprojects. Although smaller in scope and financial capacity than social funds, Literacivic may be understood as operating on some of the same principles in that it funds locally-developed subprojects and aims to support activities and initiatives which target community development issues, such as encouraging community participation and fostering community capacity.

An evaluation of this funding scheme based on the principles of a theory-based approach was carried out. The primary aim of this evaluation was to unpack the mechanisms inherent in the scheme by devising a program theory and outlining the activities, resources and factors which are assumed to be necessary to achieving program outcomes. The second aim was to examine the 'theory' on which the funding scheme is based and to analyse the processes involved in program implementation. Many funding schemes like Literacivic focus on enhancing community participation. However, it was beyond the scope of the study to examine the extent to which community participation was promoted by CDD funding. The overarching thrust of the study, therefore, was to examine how such a funding scheme operates in a community setting. The specific objectives were to: (1) develop a detailed understanding of the design, development and implementation of Literacivic; (2) outline its activities; (3) develop a detailed critique of factors that may have influenced and shaped the implementation of the initiative and; (4) explore key stakeholders' experiences of engaging with the initiative and perspectives on the program.

\subsection{Background}

Literacivic was established in Ballymun, a suburban area of North Dublin in Ireland with a population of approximately 16,500. Ballymun is one of the most economically disadvantaged neighbourhoods in Ireland and has a complex history. The area originally comprised seven 15-storey flat blocks, 19 eight-storey blocks, 10 blocks of four-storey flats and 2400 houses which were constructed between 1965 and 1969 (Somerville-Woodward, 2002). An absence of amenities in the area, coupled with neglect from authorities, contributed to deteriorating living conditions in the area. Later, during the 1980s, high tenancy turnover deepened existing socioeconomic disadvantage and social problems (Boyle, 2005). Community activism emerged in response to these issues and an unprecedented, large-scale and ongoing, regeneration plan for Ballymun was established in 1997 (Government of Ireland, 2007). This regeneration led to the radical transformation of the physical environment of Ballymun, but social and economic development has remained behind national averages (Ryan, 2004; Kintrea \& Muir, 2009).

Youngballymun was established in 2007 and comprises five services with the overarching aim of improving wellbeing and learning outcomes for children, young people and families in Ballymun. Strategically, it is dedicated to working with a wide range of statutory agencies and community-based services and organizations in order to build capacity within the community, encourage collaborative working and embed an evidence-informed and outcomes-focused service delivery model in the area. As a subsidiary to this program, Youngballymun established Literacivic in 2010 as a community-based funding scheme. Overall, the development of Literacivic was influenced by an ideological interest in, and commitment to, empowering community members and/or groups and services in Ballymun. It is often noted that, as a community, Ballymun has a strong history of social activism and self-empowerment (Boyle, 2005). Indeed, a large number of services, organizations and community/resident groups exist and operate in the area. Literacivic was established during a period of deep economic recession, when many services and organizations, as well as families, in the Ballymun community were experiencing funding and/or monetary restrictions, resource constraints and cut-backs.

The Literacivic bursary scheme was open to any resident/ residents' group, service or organization in the Ballymun electoral districts A, B, C or D. Local subprojects can be awarded a bursary ranging on a scale from $€ 200$ (\$267) up to $€ 4000$ (\$5337); (2) local coalition subprojects (i.e. subprojects developed and implemented by local individuals, groups or organizations working in collaboration) can be awarded a bursary from $€ 1000$ (\$1335) up to $€ 8000(\$ 10,679)$; and (3) local to national coalition subprojects 
(i.e. collaborations between local groups and organizations from outside of Ballymun) can be awarded a bursary from $€ 4000$ $(\$ 5337)$ to $€ 10,000(\$ 13,349)$. The scheme was administered by an independent committee (comprising four well-known individuals and academics) and subprojects must relate to awareness raising/advocacy, capacity building/leadership, and communications, events, celebrations to be eligible for the scheme.

\subsubsection{Scope of the scheme}

During the course of this study 42 applications were submitted to the scheme (following five separate calls for applications) by a range of services, agencies, groups, organizations and individuals from within Ballymun. A total of 24 applications were successful in achieving funding, amounting to a total award of $€ 142,591$ $(\$ 190,345)$. Whilst funded subprojects were diverse, funding was largely applied for and obtained by services, agencies and organizations (as opposed to individuals). Funded subprojects included: nine subprojects which involved the creation of groups, clubs or forums typically for marginalized groups in the community (e.g. young mothers, young offenders, members of the travelling community or individuals with a learning disability) and aimed at facilitating personal development, communication skills and/or encouraging broader participation within the community; eight subprojects consisted of training programs to encourage specific skill development (e.g. information technology training; creative writing); whilst seven funded subprojects involved the organization and delivery of once-off community events (e.g., dance/stage show; party; festival).

\section{Method}

\subsection{Theory-based evaluation}

This study explored, within a theory-based framework, the design of Literacivic, as well as the processes involved in the scheme. Theory-based evaluation involves articulating the 'theory' of an initiative or program by documenting the underlying set of assumptions that guide an initiative (Funnell \& Rogers, 2011). In this way, these kinds of evaluations are used to outline a 'model' of the way in which an initiative is intended to work and the causal processes and mechanisms that are anticipated to lead to intended or expected outcomes. This 'model' can then be used to assess whether and how the anticipated processes work, or do not work, by showing where steps in the causal chain produce, or fail to produce, intended results (Weiss, 1995, 1997).

Theory-based approaches have become an increasingly popular means of examining how and why a given community-based initiative works (Stame, 2004). The advantages of this approach are that it allows evaluators to elucidate, in detail, program processes and causal factors for observed effects, particularly when outputs and outcomes are not easily identifiable or directly measurable. Thus, theory-based evaluations can be used to identify the aspects of an initiative that lead to outcomes by focusing on the link between the processes and the causal mechanisms underpinning an initiative (Weiss, 1997). This type of approach is also useful in highlighting the conditions necessary for program success and the extent to which initiatives may work differently across various contexts and for different individuals and groups (Pawson \& Tilley, 1997).

Theory-based approaches are understood and applied in various ways. Weiss (1997) draws an important distinction between 'implementation theory', which identifies what is needed to translate objectives into service delivery and program operation, and 'program theory', which refers to the hypothesized causal links between the mechanisms of an intervention and their anticipated outcomes. Implementation theory could relate to testing whether specified activities are taking/have taken place as planned and linking them to intended outcomes of the program (e.g. fidelity to a particular model). Program theory, on the other hand, focuses on the mechanisms that mediate the relationship between activities and outcomes (Brousselle \& Champagne, 2011). Evaluators using a theory-based approach often tend to focus on implementation rather than program theory and emphasize sets of activities that are then linked to intermediate outcomes without necessarily demonstrating the causal mechanisms that are intended to be produced by an initiative.

Program theory approaches are increasingly common in the evaluation of social interventions and community-based initiatives (Manzano \& Pawson, 2014). Indeed, program theories are at the centre of theory-driven evaluation (Coryn, Noakes, Westine, \& Schröter, 2011). They represent a systematic modelling of the assumptions underlying a given intervention. Program theories can vary in complexity from simple and linear to highly complex and detailed representations (Rogers, 2008), but they are typically presented as a diagram that describes the relationships and interconnections between program actions and outcomes, as well as other relevant factors (Leeuw, 2003). In other words, a program theory outlines a set of sequential activities, resources and functions which are assumed by stakeholders to be important to achieving desired outcomes (Chen, 2005).

The benefits of program theory evaluation lie in its ability to highlight the logic underpinning an intervention and, in turn, to help build knowledge of how and why an intervention works, or fails to work (Jolley, 2014). The approach also serves to forefront stakeholder perspectives, and surface both underlying assumptions and implementation mechanisms. Thus, program theory can help to build a holistic understanding of social interventions (Chen, 2005). Program theory can also be used to guide evaluation (Coryn et al., 2011). That is, by making explicit the 'theory' or assumptions behind an intervention, program theory can serve to identify evaluation questions which can be examined, thereby enabling assessment of how well the theory 'stands up' to scrutiny (Donaldson, 2007).

In the context of the current research, a program theory approach was used to explicate the pathways, processes and activities involved in the scheme and which are assumed to influence outcomes. Thus, the main objective of this exploratory evaluation was to generate a program theory of Literacivic by identifying the mechanisms that are assumed to mediate the relationship between the initiative's activities and processes and its intended outcomes. It was not possible in this evaluation to examine the outcomes of the individual subprojects funded through the scheme or the extent to which the fund contributed to the development of community participation. Thus, this research focused on examining descriptive theory-guided questions focusing on the experiences of stakeholders involved in the scheme and on understanding the factors which influence the implementation of the scheme, rather than evaluative questions regarding the outcomes of the scheme.

\subsection{Data collection}

Literacivic was in the process of being set up when the evaluation began. Thus, the evaluation was able to trace the design of the initiative and explore its early implementation. Program theories are typically developed through analysis of literature and research on similar programs, reviews of program documentation, direct observation and data collection with key stakeholders (Donaldson, 2007; Rogers, Petrosino, Hacsi, \& Huebner, 2000). Data collection for this exploratory evaluation involved a multimethod qualitative approach comprising four key data sources: (i) key documentation; (ii) observational work; (iii) one-to-one 
interviews; and (iv) group discussions. These are outlined in more detail below.

The documentary analysis involved the review and critical analysis of a wide range of relevant documentation and was instrumental in identifying key concepts for further exploration, refining ideas and identifying the conceptual foundations of Literacivic. A review of all applications $(n=42)$ from across the five rounds of Literacivic funding was also conducted as part of the documentary analysis. Relevant literature on CDD funds was also critically reviewed and used to inform the theory building process (e.g. Caravalho \& White, 2004; Nikkah \& Redzuan, 2009; World Bank, 2002). In particular, we have drawn on Caravalho and White's (2004) theory of social funds to inform the development of a program theory of Literacivic. Non-participant observations were used as a complementary data source and contributed towards developing an understanding of Literacivic and its operational mechanisms. Observed events included: design and development workshops; promotional/showcasing workshops; bursary committee meetings; and events which were funded through the scheme.

Interviews and group discussions were used as the primary method of data collection and were integral to building and testing a theory of Literacivic. These were designed to explore the perspectives of those who were involved in both the operation and availing of the scheme. 16 one-to-one interviews were conducted with 15 participants. These included participants involved in the service design process $(n=3)$, Youngballymun staff involved in Literacivic implementation $(n=1)$, and Literacivic applicants $(n=11)$. Many of the applicants who participated in interviews were involved in multiple applications for Literacivic funding, whilst one individual was involved in service design and later made an application for funding. One participant was interviewed on two occasions, before and after submitting an application for funding. Two group discussions were also conducted with all four members of the bursary committee. Informed consent was obtained from all participants and all interviews and group discussions were audio recorded (with consent) and transcribed verbatim.

\subsection{Data analysis}

The data was analyzed using a standard thematic analysis (Braun \& Clarke, 2006) which involved several stages including: familiarization, summarising and paraphrasing, coding, categorization and triangulation. The familiarization stage involved an indepth reading of the data and the generating of detailed summaries. Summaries included paraphrasing quotes from transcripts and focus groups, encapsulating what occurred at events, meetings, and consultations, and recapping and reviewing documents, reports and published literature. This was followed up by identifying initial codes to explain the data. These codes were developed by interrogating the data and linking narrative content to larger, more general processes or categories which capture the meaning of the data. This led to specification of attitudes, relationships, activities and events which were inherent in the data. Coding was developed from the data and also by applying a priori hypotheses developed from key literature and consultations with key stakeholders. The later stages of analysis involved the categorization of codes into overarching themes, finalising conclusions and interpretations, whilst also determining the strength and depth of the findings or themes. For example, we assessed the prevalence of attitudes or the nature and range of processes and activities.

Considerations of quality and validity are paramount in qualitative research (Silverman, 2013). A number of steps were undertaken to ensure a rigorous approach to data analysis including: (i) the triangulation of findings across multiple sources of data, as well as awareness of, and reference to, relevant literature; and (ii) participant feedback or 'respondent validation' was also obtained using transcript reviews. All participants were provided with their anonymized transcripts and asked to review and reassess their comments and perspectives. This provided participants with an opportunity to change their comments/ statements and to clarify meanings or contradictions. Respondent validation was critical to the verification of our analysis and to the identification and exploration of the final key themes.

\section{Findings}

\subsection{The design and theory of Literacivic}

In early 2010, a working group for Literacivic was established which brought together a diverse range of stakeholders to contribute to the service design process. This working group comprised a number of members from both local and national organizations and agencies. At the outset, it was envisaged that the development of Literacivic would involve four or five workshops, followed by a wider community consultation process. However, the design process concluded with three working group meetings, one community consultation event and a service launch. Overall, the impetus for Literacivic centred on an interest in empowering or enabling the 'voice' of the Ballymun community (Youngballymun, 2010). Subsequently, the promotion of "civic literacy" emerged as the cornerstone of the funding scheme which, in this context, reflected a focus on promoting community participation:

It is about everything that you do, being able to do those things, but also to do everything else as well-to be part of the community, be part of your family, to be able to contribute to civic life and everything, how you operate in the community is the way I would see it. In order to do that you need skills and you need knowledge and you need links and networks. [Participant 5; Bursary committee member]

If you can help people to develop and to grow in some way as part of the process, hopefully at some stage they would become better citizens. What is the spin-off of that? They don't have to be activists. We don't need huge activist groups going around Ballymun but ordinary people who have the sense of belonging in Ballymun, a sense of identity. [Participant 4; Bursary committee member]

The decision to establish Literacivic as a funding scheme appears to have emerged around the third working group meeting and was subsequently adopted by the Youngballymun executive. While the service design process for Literacivic was described by one participant as "quite a perplexing process" [Participant 12; Working group member], there also appears to have been wideranging support for the idea of a community-based fund which would be available to support community engagement and development. Thus, Literacivic was established as a bursary scheme that was open to all members of the Ballymun community. Information leaflets, posters and brochures were developed; a service launch and, at a later stage, two workshops were held to publicize and promote the availability of the scheme and create awareness of its remit.

The theory of the social funding scheme is shown in Fig. 1. Underpinning the scheme is the assumption that the locally developed nature of subprojects can better support positive community development. Promotional efforts create awareness of, and interest in, the scheme. Individuals, groups/organizations and/or coalitions prepare and submit proposals for subprojects. An 


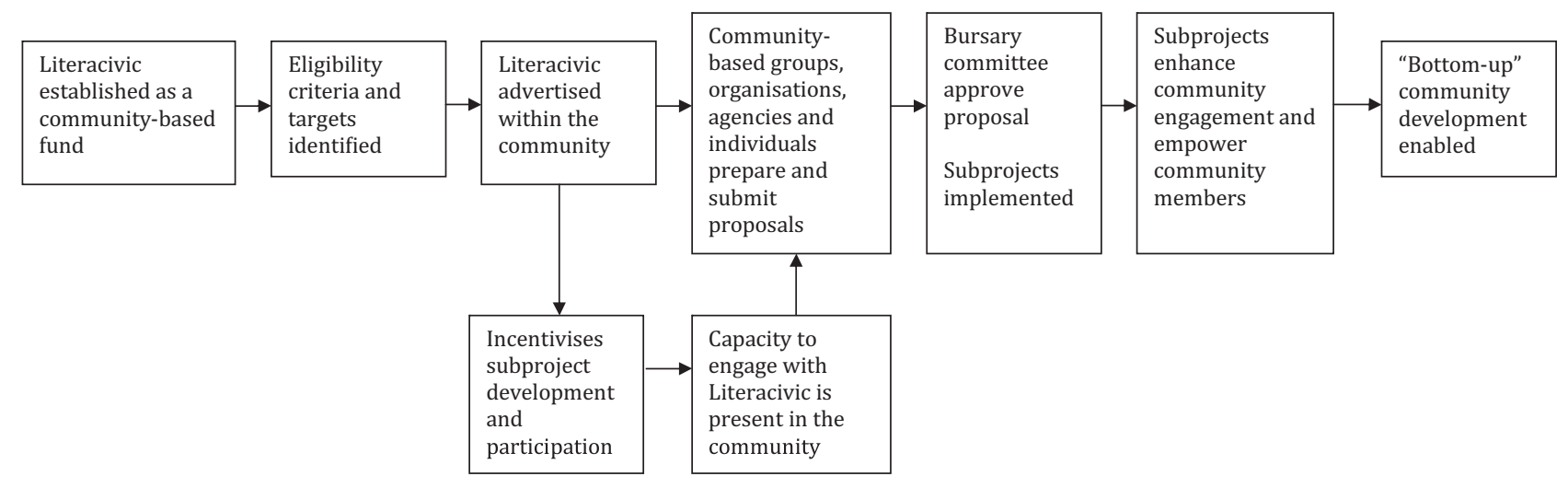

Fig. 1. The theory of Literacivic.

independent committee and eligibility criteria are assumed to enable unbiased access to the fund and ensure that subprojects maximize the benefits for the community. The theory also implies that the development and implementation of funded subprojects can result in the development of community engagement and, in turn, contribute to community empowerment. Funders did not have any responsibility for any aspect of subproject implementation or completion.

Some broader assumptions underlying the scheme are that receptiveness to, and the capacity to engage with, Literacivic exists within the community and that the Literacivic fund can function as an incentive for locally-based organizations or individuals to develop subprojects that promote community participation. It is assumed, therefore, that Literacivic can operate as a change strategy by promoting and supporting the local identification of needs and providing a platform for bottom-up community development.

The process of outlining a program theory of Literacivic helped to identify key theory-guided questions relating to the implementation of the scheme within the community. For example, some of the key assumptions inherent in the theory of Literacivic were that eligibility criteria ensured benefits for the local community and that there was equitable access to the scheme among community members. In practice, this means that the scheme ought to be viewed positively by the community, there is ample community capacity to participate in the scheme and that funding mechanisms support the identification of subprojects which, in turn, promote community-driven development and beneficial outcomes for the community. Thus, in order to critique the theory of Literacivic, we focused on exploring: (a) how the scheme was received by key stakeholders; (b) barriers and/or facilitators to engagement with the scheme; (c) the reach and nature of engagement with the scheme; and (d) the experiences of individuals, groups and organizations that engaged with Literacivic.

\subsection{Engagement with the scheme}

Overall, positive perceptions of the funding scheme were in evidence. The community-based applicants demonstrated an understanding of the conceptual basis of the scheme which centred on the importance of community participation and empowerment. Additionally, the goals of Literacivic were perceived as corresponding with the goals of locally-based organizations and services. Unsurprisingly, the experience of a successful application was viewed positively and the scheme was considered to provide a positive opportunity to promote community engagement. Overall, participatory processes were perceived to be a key driver for community development and these findings suggest there was general support for the idea of a funding scheme to support bottom-up community development.

[Literacivic] is specifically for certain types of training in the community and advocacy and all of that and it is great to have something like that to tap in because, believe me, it is so hard to get funding out there around building the capacity of people, around leadership skills and advocacy [Participant 1; Bursary applicant]

[I] thought it was really exciting, I was really glad that it's civic literacy, that it's looking. . . at the bigger picture, the context and the social and political side of things. And I thought, yep all of it's really great, exactly the type of work that I'd be trying to do. [Participant 8; Bursary applicant]

However, some concern arose over a lack of engagement with the scheme due to the perceived low level $(n=42)$ of applications received. Notably, multiple applications were received from some organizations and services. For example, 8 applications were received from a local youth work centre and 5 applications were received from another family-oriented service in the area. Disadvantage and marginalization can restrict the ability of individuals or groups to participate within their community and result in social exclusion. Non-participation, however, does not necessarily represent social exclusion (Shortall, 2008). Community members may choose not to participate if, for example, they are already engaged at a local level, or feel that they have a strong social network. However, a number of issues did emerge during the early stages of implementation relating to the accessibility of the scheme. The 'branding' of the scheme was viewed as potentially off-putting for community members and may have acted as an impediment for certain groups applying for funding. The name itself, 'Literacivic', was viewed pejoratively and it was thought that this language did not convey the relevance of the scheme to the community and might undermine scheme uptake, particularly amongst more marginalized community members:

Like 'Literacivic Bursary'-people aren't used to that type of language, and that is not putting people down. People working in the community wouldn't use that type of [language], it just wouldn't be used. [Participant 2; Bursary applicant]

I think there is a problem with the name and I don't mean to harp on it. I am fine with the name because I understand what it is but there are a lot of groups out there that don't. And I think that is why they are not getting a huge influx of applications, I 
am assuming, I think it was said at the last thing that they are not. [Participant 1; Bursary applicant]

For a number of participants, their experience of engaging with the funding scheme was not satisfactory or constructive. Indeed, dissatisfaction was expressed both with the application process and the subsequent feedback received from the bursary committee. There was also a perceived lack of clarity in the funding eligibility criteria, which was experienced as a significant impediment to the application process as it contributed to uncertainty regarding the suitability of the proposed subproject and the likelihood of obtaining the funding:

I wasn't very clear about the criteria and I still don't think they are clear [...]. They are very general criteria. There were criteria for you to bear in mind when you were applying according to which they were going to judge the applicants and decide where the money was going to. [Participant 11; Bursary applicant]

This uncertainty was compounded by a perceived lack of transparency around the funding award process. Clarity is a crucial factor in the implementation of these kinds of schemes (Crisp, Swerissen, \& Duckett, 2000); however, applicants felt that there was a lack of openness regarding why and how the award is made and the kind of criteria that are applied by the committee, particularly in the case of unsuccessful proposals. Thus, dissatisfaction with the level of clarification and detail received in respect of the unsuccessful application was apparent and this led to some negative perceptions of the scheme:

It felt initially a bit like a slap in the face, you know. Like we filled it [the application form] out to what we felt they were saying [about Literacivic] and then ... 'Well, actually that's not what we're looking for now'. So it did feel like a bit of a slap in the face. [Participant 2; Bursary applicant]

It [feedback provided] was negative, I just got an email, and it took a long, long time to get it... [...]'We have serious reservations', 'serious reservations' is very strong, I mean I thought 'what's that about?' One of the committee members rang and asked for feedback, and he was told that there was no feedback, so that was it [...]. There is very little knowledge around who actually did get the funding. A lot of people I spoke to did not get the funding and didn't know why. It's a pity, I think it's a missed opportunity [...] and I think there is a lack of transparency as well. [Participant 11; Bursary applicant]

The qualitative interviews and fieldwork illustrated that there were also some concerns that the scheme could be inaccessible for certain groups in practicable terms, or perhaps more specifically, that it would be more accessible for others with greater resources and levels of experience. These findings raise questions regarding the nature of participation in the scheme. While Literacivic invites proposals from the Ballymun community, this rests on the assumption that community members have the requisite skills to prepare and submit proposals. Indeed, the scheme places particular value on supporting community development and increasing community participation. In fact, it was hoped that Literacivic would attract applications not only from practitioners and their organizations or services, but also from grass roots community members such as parent groups and individual residents. However, the process of developing an application, coupled with the lack of explicit guidelines, was viewed as potentially exclusionary for some more disadvantaged individuals and groups and/or those without prior experience of preparing funding applications. There was also a perception that those who had engaged with Literacivic comprised a number of relatively advantaged groups and that more marginalized groups were excluded from the scheme due to a lack of skills needed to engage in a written application process. Indeed, the vast majority of applications for funding were received from established organizations and services within the Ballymun community. Many of these groups had previous experience of funding applications and, indeed, setting up and establishing community-based programs:

Certainly it takes, you know, two or three days to write that and I'm, I have the skills to do that. So I think anybody else may well have some trouble with that. [Participant 19; Bursary applicant]

If it was for the people in Ballymun, I can't see many residents in Ballymun having the capacity or the ability to write a thorough application for them. I know a lot of people who are very clever or streetwise, that have great ideas, but ask them to fill in an application form and it's very difficult. [Participant 11; Bursary applicant]

\subsection{The social funding scheme as a change strategy for community participation}

Applicants described the implementation of funded subprojects as having significant positive benefits for their organization and/or group, as well as the individuals who participated in funded subprojects. Although funded subprojects were typically small in scope, the nature or quality of participation was considered paramount. Indeed, if community development and social inclusion schemes are to be successful, they ought to offer an opportunity for personal development and involve high quality engagement (Skinner, Zakus, \& Cowell, 2008). According to those who had obtained funding, subprojects were viewed as having promoted positive outcomes for the individuals who participated in funded subprojects. For example, interviewees felt that opportunities had been provided for those community members to develop personal skills, link more formally into communitybased services and, in some cases, to further their involvement in the community, build social networks and access additional services and/or supports. Thus, subprojects were seen as providing opportunities for individuals to strengthen their participation in other community activities, as well as potentially breaking down barriers to engagement.

The young women [who participated in a funded subproject] did perceptively grow in confidence from the beginning of the project to the end. [Participant 13; Bursary applicant]

All the time you are building people's self-esteem, you are building their confidence, you are giving them a voice, you are letting them know their voice is valuable. [Participant 2; Bursary applicant]

Following that, [subproject participants] have taken part in other things in the area like painting the mural there on Ballymun Road and doing some other gardening projects as well. There is much, much more of a pride with them, that kind of way, and obviously the fact that their literacy levels have improved and they are able to partially participate in other things now because of that [funded subproject]. [Participant 17; Bursary applicant]

Funding was considered by participants to have provided an important opportunity for organizations and groups to strengthen 
their interaction with the community and become more creative and innovative in the manner in which they engage with community members. For example, funding was perceived as enabling organizations to engage with groups whom they would otherwise find hard to reach, as well as enabling subprojects to become more expansive, thereby facilitating better outcomes. The funding was also understood as facilitating access to external expertise, practical resources and equipment that may otherwise have been beyond the reach of the applicants and, in turn, contributing to capacity development for those organizations and services which had been successful in obtaining funding.

I particularly wanted to work with new groups on this project. It's very easy to hand a project like this to groups that you have a relationship with or that you've worked with before. We kind of set the challenge that would really try to go further out into the community. [Participant 18; Bursary applicant]

What it means is that we get to do a decent enough project that has impact. You could rustle together a four week [project] and say you've done a four week [project]. I think that most projects need a decent length of time, so if you can get a decent amount of funding, that allows that. [Participant 18; Bursary applicant]

The findings also suggests that, to some extent, the scheme informed a process of learning and reflective practice whereby applicants were prompted to think about how small-scale subprojects might best impact on community participation and engagement. Thus, engaging with Literacivic was viewed as a useful learning experience which led applicants to consider the impact and likely consequences of their intended activities and helped to heighten awareness of community needs.

It was really good for me to think about what ... opportunities can I create for them and where can we offer them something bigger and better, I suppose. Rather than being stuck in, ok let's create another project, let's create another group of young people coming together and doing $\mathrm{x}, \mathrm{y}$ and $\mathrm{z}$. [Participant 16; Bursary applicant]

I think it has highlighted to us [...] that we need to be now more proactive [...]. Hopefully get the young women more engaged on a political, civic, get them more aware and more involved and show them, yes you can make changes. Get them collectively involved in making changes for themselves which only empowers them and informs them. So that is kind of our target from September. Our plan for this year was to be more proactive in our plan, in working with the young people. [Participant 15; Bursary applicant]

\section{Discussion}

As outlined above, an evaluation of a community-based funding scheme was carried out which focused on articulating and assessing the underlying assumptions inherent in the design and implementation of the scheme and the causal sequence by which it aims to produce outcomes for the community. The key aim of the scheme is to support, through financial assistance, the development of community participation. In other words, Literacivic attempts to embody a change strategy which facilitates 'bottom-up' community development. The program theory approach used in this research enabled us to identify the mechanisms by which the funding scheme attempts to engage community members and promote positive outcomes for the community. This program theory was also used to identify descriptive, theory-guided research questions which were tested out to examine how the scheme is operating in practice and whether some of the assumptions underpinning the scheme are being met.

Overall, positive perceptions of the funding scheme and its role within the community were in evidence. The funding scheme also appeared to promote learning and reflection amongst applicants to the scheme around how community participation can be addressed through small-scale community development initiatives. For example, the application process was viewed as a learning experience, even when the application was unsuccessful. There were, however, some negative experiences of engaging with the scheme. These were related to a perceived lack of appropriate feedback on unsuccessful proposals and a lack of clarity surrounding funding eligibility criteria which, in turn, undermined the possibilities learning as a result of engaging with the scheme. This highlights the need to support a more general process of learning and capacity development through the development of subproject funding proposals. Thus, effective communication surrounding funding mechanisms and eligibility criteria are essential in order to ensure that engagement with the scheme is experienced positively (Crisp et al., 2000).

Beneficiaries of the scheme reported positive outcomes for individuals who participated in subprojects, such as the encouragement and facilitation of community participation through funded subproject activities, as well as the development of capacity amongst those that had access to funding. Participation in social activities is important not only for maintaining a sense of belonging but also to facilitate longer-run community development (Anderson \& Bell, 2003; Boneham \& Sixsmith, 2006). However, the findings reported here are based on the experiences of those individuals and/or organizations that were funded through the scheme and the impact of funded subprojects on individual or community outcomes was not explored. It is, therefore, not possible to make definitive conclusions about whether or not the mechanisms underpinning the scheme could support the development of such community participation. Longer-run research, conducted beyond the level of the scheme itself, would be needed to 'test out' the assumptions that the mechanisms inherent in the fund can adequately support the identification of subprojects which, in turn, promote enhanced community participation and engagement.

Some interesting issues, however, arose around the nature of participation in the scheme. Community input into the design and development of the scheme itself was limited and community consultation did not appear to influence the scope and nature of the scheme. Moreover, funding was largely applied for and obtained by formal institutions/organizations, rather than community residents. Consequently, the participation of community residents can be perceived as being located within projects, events and/or programs, whilst the power of existing institutions is essentially reinforced. Indeed, the scheme could be argued to effectively perpetuate existing power structures, whereby community members are limited to participation in programs, whilst decision-making processes remain seated within existing institutions, organizations and services or external authorities (Babajanian, 2005; Eversole, 2010).

Indeed, the accessibility of Literacivic funding and the ability of more marginalized members of the community to engage with the scheme were highlighted as potentially problematic. Critics of social funds argue that communities with greater resources have a greater likelihood of being successful in attaining funding (White, 2002). Indeed, the initiative to obtain CDD funds has been found to be frequently driven by "prime movers" (Caravalho \& White, 2004: 154). Thus, a bi-directional relationship between community resources and social funds is evident (Carvalho \& White, 2004). That is, social funds can help to promote community development, 
but elite members of the community are more likely to be able to access and benefit from these kinds of funding sources. In the context of Literacivic, access to funding arguably helped towards the development of capacity and facilitated access to practical and human resources. Indeed, the funding scheme was available during a period of economic recession which had severe implications for many organizations and services in this disadvantaged community. The availability of funding, therefore, could be argued to have helped to develop useful subprojects for the community which may otherwise have been inaccessible. Nevertheless, those who already have access to resources and can successfully conform to eligibility criteria were arguably more likely to gain funding, whilst more disadvantaged members of the community were perceived as being excluded from the scheme. This evidence qualifies the support for the assumption that Literacivic can promote a change process, whereby community members are empowered to drive community development from the bottom up.

To sum up, there are some weak links in the theory of the scheme. Negative experiences of engagement with the scheme may undermine the extent to which the fund may support a process of community engagement. Moreover, the scheme was seen as more accessible to certain individuals or groups and the assumption that a social funding scheme can support the participation of more marginalized groups would appear to be somewhat flawed. The processes inherent in the scheme may, in fact, reinforce the resources and positions of the relatively better off sectors of the community. Thus, the extent to which Literacivic can support a generalized process of community engagement is questionable.

\section{Lessons learned}

Some study limitations must be noted. First, this was an exploratory study which was conducted at the project level. Thus, the insights into the scheme and the perceived outcomes of specific Literacivic-funded subprojects were obtained from key stakeholders who had been successful in securing funding and in developing and implementing these projects. It may be the case, therefore, that interviewees involved in this research had a vested interest in, and were more likely to have focused on, the positive outcomes and aspects of the subprojects for which they had obtained funding, whilst overlooking any potentially negative aspects. Nevertheless, the theory-based framework adopted here is useful for identifying the assumptions which underpin such community-based schemes and for detailing how an initiative is purported to work. Indeed, the central value often ascribed to program theory evaluation is that it can contribute to understanding how a given program works and, in turn, enable the identification of key mechanisms which are critical to program success or, conversely, where program and/or implementation failures are likely to occur (Donaldson \& Lipsey, 2006). Development of a program theory may also be used to guide and inform the future management and monitoring of such community-based schemes. Thus, such findings can provide a useful tool in the continued implementation of these kinds of schemes and the communication of their intended outcomes (Chen, 2005).

Further limitations of the current study are its exploratory nature and the absence of assessment of the longer-term impact of Literacivic. Examining the impact of the scheme on individual community members and community participation was also beyond the scope of this evaluation. Thus, many aspects of the theory of Literacivic could not be properly tested. Nevertheless, the use of a program theory approach enables program developers and evaluators to ask critical questions about what community-based interventions and schemes are attempting to do, and to examine the evidence in relation to whether or not the scheme/intervention is likely to be successful (Funnell \& Rogers, 2011). That is, the execution of a theory-based evaluation can help to provide a useful schematic overview and important insights into what these kinds of community-based funding schemes are trying to achieve and how their objectives and interim achievements aim to contribute to positive longer-term outcomes. Thus, this kind of evaluation can help program designers and implementers, as well as researchers develop evaluative questions which can be tested at a later stage to examine whether the scheme has met its intended goals (Coryn et al., 2011).

Overall, the findings can be considered helpful in highlighting some the conditions which may undermine the effectiveness of small-scale CDD funds. For example, the study findings highlight the potential challenges in engaging more marginalized groups in community-based funding schemes and the importance of ensuring that grievances and/or dissatisfaction does not arise as a result of the non-award of funding. Thus, a more targeted approach and/or additional supports may be needed to ensure that marginalized groups engage with, and are not at a disadvantage when applying for, funding schemes. Appropriate and adequate advertizement of funding schemes, their intended mechanisms and functions, as well as clear eligibility criteria, are also important in mitigating the potential risks of dissatisfactory experiences of engagement with these schemes and promoting learning experiences. Our findings suggest that the fund was beneficial in enhancing the resources available to services and organizations during a period of economic recession. Thus, these kinds of funding schemes may be suited to enhancing tangible capital and creating an enabling environment, whilst smaller scale community funds may also be a useful, flexible mechanism which can be deployed strategically to support community capacity in times of need.

\section{Acknowledgements}

This research was funded by Youngballymun with financial support from the Atlantic Philanthropies and the Department of Children and Youth Affairs. We would like to thank all participants who took part in this research, as well as Youngballymun and the Literacivic bursary committee for their support of the research. The views expressed herein are those of the authors and not necessarily those of Youngballymun or the Literacivic bursary committee. We also gratefully acknowledge the help and expertise of Prof. Elliot Stern and Dr. Michael Donnelly during the execution of this research.

\section{References}

Anderson, C. D., \& Bell, M. M. (2003). The devil of social capital: A dilemma of American rural sociology. In P. Cloke (Ed.), Country visions (pp. 232-244). Essex: Pearson Education.

Arcand, J. L., \& Bassol, L. (2006). Does community driven development work? Evidence from Senegal Washington, DC: World Bank Accessed 19th June 2014 from 〈http:// siteresources.worldbank.org/EXTSOCIALDEVELOPMENT/Resources/2443621164107274725/3182370-1164201144397/ Does_Community_Driven_Development_Work.pdf

Babajanian, B. V. (2005). Bottom-up and top-down? Community development in PostSoviet Armenia: The social fund model. Social Policy \& Administration, 39, 448-462.

Boneham, M. A., \& Sixsmith, J. A. (2006). The voices of disadvantaged older women in a disadvantaged community: Issues of health and social capital. Social Science and Medicine, 62, 269-279.

Boyle, M. (2005). Sartre's circular dialectic and the empires of abstract space: A history of space and place in Ballymun, Dublin. Annals of the Association of the American Geographers, 95, 181-201.

Braun, V., \& Clarke, V. (2006). Using thematic analysis in psychology. Qualitative Research in Psychology, 3, 77-101.

Brousselle, A., \& Champagne, F. (2011). Program theory evaluation: Logic analysis. Evaluation and Program Planning, 34, 69-78.

Carvalho, S., \& White, H. (2004). Theory-based evaluation: The case of social funds. American Journal of Evaluation, 25, 141-160.

Chen, H. T. (2005). Practical program evaluation: Assessing and improving planning, implementation, and effectiveness. Thousand Oaks, CA: Sage. 
Cornwall, A. (2003). Whose voices? Whose choices? Reflections on gender and participatory development. World Development, 31, 1325-1342.

Cornwall, A. (2008). Unpacking ‘Participation': Models, meanings and practices. Community Development Journal, 43, 269-283.

Coryn, C. L. S., Noakes, L. A., Westine, C. D., \& Schroeter, D. C. (2011). A systematic review of theory-driven evaluation practice from 1990 to 2009. American Journal of Evaluation, 32, 199-226.

Crisp, B. R., Swerissen, H., \& Duckett, S. J. (2000). Four approaches to capacity building in health: Consequences for measurement and accountability. Health Promotion International, 15, 99-107.

Donaldson, S. I. (2007). Program theory-driven evaluation: Strategies and applications. New York, NY: Psychology Press, Taylor and Frances Group.

Donaldson, S. I., \& Lipsey, M. W. (2006). Roles for theory in contemporary evaluation practice: Developing practical knowledge. In I. Shaw, J. C. Greene, \& M. M. Mark (Eds.), The handbook of evaluation: Policies, programs, and practices (pp. 56-75). London, UK: Sage.

Eversole, R. (2010). Remaking participation: Challenges for community development practice. Community Development Journal, 47, 29-41.

Fritzen, S. A. (2007). Can the design of community-driven development reduce the risk of elite capture? Evidence from Indonesia. World Development, 35, 1359-1375.

Funnell, S. C., \& Rogers, P. J. (2011). Purposeful program theory: Effective use of theories of change and logic models. San Francisco, CA: Jossey-Bass.

Government of Ireland (2007). Ballymun regeneration. Dublin: Stationary Office.

Jolley, G. (2014). Evaluating complex community-based health promotion: Addressing the challenges. Evaluation and Program Planning, 45, 71-81.

Leeuw, F. L. (2003). Reconstructing program theories: Methods available and problems to be solved. American Journal of Evaluation, 24, 5-20.

Kintrea, K., \& Muir, J. (2009). Integrating Ballymun? Flawed progress in Ireland's largest estate regeneration scheme. Town Planning Review, 80, 83-108.

Labonne, J., \& Chase, R. S. (2011). Do community-driven development projects enhance social capital? Evidence from the Philippines. Journal of Development Economics, 96, 348-358.

Mansuri, G., \& Roa, V. (2003). Evaluating community-based and community-driven development. Washington, DC: World Bank.

Manzano, A., \& Pawson, R. (2014). Evaluating consent to deceased organ donation: The need for programme theory. Journal of Healthcare Organization \& Management, 28 366-385.

Narayan, D., \& Ebbe, K. (1997). Design of social funds: Participation, demand orientation and local organisational capacity. Washington, DC: World Bank.

Nikkah, H. A., \& Redzuan, M. (2009). Participation as a medium of empowerment in community development. European Journal of Social Sciences, 11, 170-176.

Nuttavuthisit, K., Jindahra, P., \& Prasarnphanich, P. (2014). Participatory community development: Evidence from Thailand. Community Development Journal. http:/ dx.doi.org/10.1093/cdj/bsu002

Pawson, R., \& Tilley, N. (1997). Realistic Evaluation. London: Sage.

Perrett, H. (2004). Community development funds: Emerging evidence for project design. IFAD Retrieved 24 July 2014 from /http://www.ifad.org/targeting/doc/imi_vol6.pdf).

Rawlings, L. B., Sherburne-Benz, L., \& Van Domelen, J. (2003). Evaluating social funds: A cross-country analysis of community investments. Washington, DC: World Bank.

Rogers, P., Petrosino, A., Hacsi, T., \& Huebner, T. (2000). Program theory evaluation: Practice, promise and problems. In P. Rogers, A. Petrosino, T. Hacsi, \& T. Huebner (Eds.), Program theory evaluation: Challenges and opportunities, new directions in evaluation series (pp. 5-13). San Francisco, CA: Jossey-Bass.
Rogers, P. (2008). Using programme theory to evaluate complicated and complex aspects of interventions. Evaluation, 14, 29-48.

Ryan, G. (2004). Get it right the first time: An education strategy for Ballymun. Ballymun: Ballymun Partnership.

Shortall, S. (2008). Are rural development programs social inclusive? Social inclusion, civic engagement, participation and social capital: Exploring the difference. Journal of Rural Studies, 24, 450-457.

Silverman, D. (2013). Doing qualitative research: A practical handbook (4th ed.). London: Sage.

Skinner, S., Zakus, F. H., \& Cowell, J. (2008). Development through sport. Building social capital in disadvantaged communities. Sport Management Review, 11, 253-275.

Somerville-Woodward, R. (2002). Ballymun, a history: Volumes 1 E' 2C.1600-1997. Ballymun: Ballymun Regeneration Ltd.

Stame, N. (2004). Theory-based evaluation and types of complexities. Evaluation, 10, $58-76$.

Tandon, R. (2008). Participation, citizenship and democracy: Reflections on 25 years' of PRIA. Community Development Journal, 43, 284-296.

Van Domelen, J. (2006). Social capital in the operations and impacts of social investment funds. In A. J. Bebbington, M. Woolcock, S. Guggenheim, \& E. A. Olsen (Eds.), The search for empowement: Social capital as an idea and practice at the World Bank. Bloomfield: Kumarian Press.

Weiss, C. (1995). Nothing as practical as good theory: Exploring theory-based evaluation in complex community initiatives for children and families. In J. P. Connnell, A C. Kubisch, L. B. Schorr, \& C. H. Weiss (Eds.), New approaches to evaluating community initiatives: Concepts, methods, and contexts (pp. 65-92). Washington, DC: Aspen Institute.

Weiss, C. (1997). Theory-based evaluation: Past, present and future. New Directions for Evaluation, 76, 41-55.

White, H. (2002). Social funds: A review of the issues. International Development, 14, 605-610.

World Bank (2002). Social funds: Assessing effectiveness. Washington, DC: World Bank. Youngballymun (2010). Progress, partners, plans: Youngballymun implementation plan. Ballymun: Youngballymun.

Dr Gráinne Hickey holds a Research Program Manager position in the Department of Psychology, Maynooth University, Ireland.

Dr Sinéad McGilloway is a Senior Lecturer in psychology and Director of the Mental Health and Social Research Unit at Maynooth University, Ireland.

Dr Morgan O'Brien is a lecturer in sociology and youth and community studies in the School of Business and Humanities, Institute of Technology, Carlow, Ireland.

Yvonne Leckey is a Senior Research Assistant and Fieldwork Coordinator in the Department of Psychology, Maynooth University, Ireland.

Prof Maurice Devlin is Jean Monnet Professor and Director of the Centre for Youth Research and Development in the Department of Applied Social Studies at Maynooth University, Ireland. 